\title{
Choice of a warning signal or none in several unavoidable-shock situations'
}

JOAN S. LOCKARD

UNIVERSITY OF WASHINGTON ${ }^{2}$

\begin{abstract}
In a two-compartment grid shuttle box, rats tended to prefer a $1 / 2 \mathrm{sec}$. or a $5 \mathrm{sec}$. warning signal over no signal preceding unavoidable shock. They did not prefer either a $0 \mathrm{sec}$. or random signal-shock interval over no signal. And they did not tolerate more shock to obtain a signal than they had to tolerate in a nosignal compartment.
\end{abstract}

\section{Problem}

Studies by Knapp, Kause, \& Perkins (1959), Lockard (1963), and Perkins, Levis, \& Seymann (1963) found that rats prefer a warning signal over no signal preceding unavoidable shock. The present experiment continued the investigation of this warning-signal preference. The parameters were signal-shock interval and shock intensity. Four questions were asked: (a) Since previous studies used relatively long signal-shock intervals $(30$, 5 and $3 \mathrm{sec}_{\text {。) }}$ would Ss prefer a warning signal if the interval were quite short (1/2 sec.)? (b) How would Ss behave with a signal simultaneously paired with shock (0 sec. signal-shock interval)? (c) Would Ss tolerate more shock in order to obtain a warning signal than they would have to tolerate in a no-signal situation? (d) What would be the effect in extinction if the shock were maintained on a random schedule rather than discontinued altogether (as in Lockard, 1963)?

\section{Subjects}

The $\mathrm{Ss}$ were 48 Sprague-Dawley female albino rats (4 replications of 12 animals each) approximately 90 days old at the time of testing. Apparatus

The same pair of two-compartment grid shuttle boxes employed by Lockard (1963) were used here. In the wall separating the two compartments of each box were two swinging doors-one door opened into one compartment and the other door into the other compartment. The doors transmitted no light when closed and were easily opened by the Ss. In each of the compartments were two glass signal-light windows, the luminance of which was $426.06 \mathrm{~mL}$. A constant-curren circuit (Campbell \& Teghtsoonian, 1958) provided the shock: 60cycle ac, administered through the grid floors of an alternate-bar system with a 760 v source and either a 3.22 or 3.44 megohm limiting resistor in series with $S$. The grid floors were mounted such that $S^{\prime}$ s weight depressed the floors, closing or opening relay contacts which permitted clock and counter measures of S's whereabouts. Four Hunter-Brown electric timers regulated the duration of the signal, of the shock, and of the signal-shock intervals. Trials were programmed by a three-channel tape programmer.

\section{Procedure and Design}

The $\mathrm{Ss}$ were given a choice in the two-compartment box between a signal light plus shock and only shock. On each trial the two grids were electrified simultaneously so that the Ss could not escape the shock except by an accidental grasping of certain grid-bar combinations. A trial consisted of the presentation of a blinking light (CS) through the windows and a shock (US) through the grid floors. The CS always came on in only one of the two compartments and always in the same compartment for any single $S$. One side of the box was the CS compartment for half the $\mathrm{Ss}$ and the other side was the CS compartment for the rest of the Ss. Each $S$ was tested individually for 24 days and received 30 trials a day at a variable intertrial interval (from US to US), the mean of which was $1.9 \mathrm{~min}$.

For the first two days the $\mathrm{Ss}$ were run in mock experimental sessions-only the experimental treatments were omitted. Operant level measures of time and number of trials (had the trials been presented) $\mathrm{S}$ spent in each compartment were recorded. The $48 \mathrm{Ss}$ were then assigned to one of eight six-animal groups equated for operant level. The eight groups composed a $2 \times 4$ design. There were two levels of shock $(.236 \mathrm{ma}$ and $.221 \mathrm{ma})$ and four different signal-shock interval s ( $5 \mathrm{sec} ., 1 / 2 \mathrm{sec} ., 0$ sec., and Random). For four of the groups (Shock Same) the same amount of current $(.236 \mathrm{ma})$ was delivered to both compartments. For the other four groups (Shock Different) the grids were differentially electrified: during shock the current through $S$ in the signal compartment was $7 \%$ more $(.236 \mathrm{ma})$ than in the no-signal compartment $(.221 \mathrm{ma})$. For 12 days of acquisition, the signal was presented either $5,1 / 2$ and 0 sec. before shock or at random times between shock; and for 10 days of extinction, at random times between shock for all Ss.

\section{Results}

The number of trials and the amount of test-session time Ss spent in the CS compartment correlated almost perfectly, so that only the former is presented. Moreover, the number of trials Ss accidentally avoided the US did not increase differentially for treatments and, therefore, is not considered further.

Group data (collapsed across days) for shock intensity and signal-shock interval groups are presented in Fig. 1. Considering shock intensity first, the mean performance (collapsed across CS-US intervals) of the Shock-Same groups differed from that of the ShockDifferent groups in both acquisition $(\mathrm{F}=6.45 ; \mathrm{df}=1 / 40$; $\mathrm{p}<.05)$ and extinction $(\mathrm{F}=4.41 ; \mathrm{df}=1 / 40 ; \mathrm{p}<.05)$. The Shock-Same groups, with the same amount of shock in each compartment, tended to spend more trials in the CS compartment; while the Shock-Different groups, which had $7 \%$ more shock in the CS compartment, tended to spend more trials in the compartment with less shock. The difference in mean performance is specifically attributable to the difference between the Shock groups with the $1 / 2$ sec. CS-US interval in both acquisition ( $F=13.56$; df $=1 / 10 ; p<.01)$ and extinction $(\mathrm{F}=19.25 ; \mathrm{df}=1 / 10 ; \mathrm{p}<.01)$. Although the plotted data for Shock groups with the $5 \mathrm{sec}$. interval would seem to differ considerably, these differences, as well as those between the 0 sec. groups and between the Random groups, were not significant in either acquisition or extinction.

The CS-US interval data are considered separately for each of the shock-intensity groups. With shock the s a me in both compartments, the performance of the interval groups differed slightly in acquisition $(F<1)$, but quite noticeably in extinction $(F=3.99 ; \mathrm{df}=3 / 20$; $\mathrm{p}<$ 。05). The groups in acquisition did spend at least 


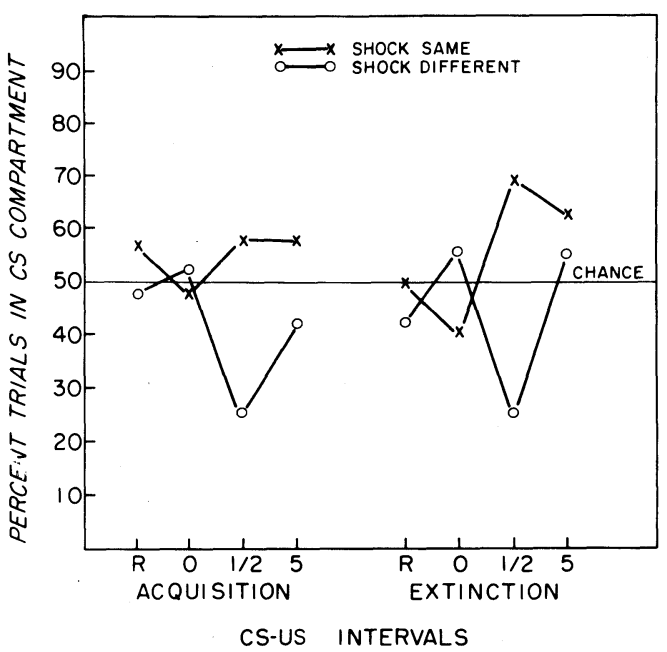

Fig. 1. Percentage of trials, for each shock intensity and CS-US interval group, Ss were in the CS compartment in acquisition and extinction.

half of the trials in the CS compartment and, in extinction, the $1 / 2 \mathrm{sec}$. and $5 \mathrm{sec}$. groups continued the trend and spent considerably more trials in the CS compartment. A Duncan Range test (Duncan, 1955) on the extinction data showed the difference between the $1 / 2$ sec. and 0 sec. groups to be significant $(p<.01)$; the difference between the $5 \mathrm{sec}$. and $0 \mathrm{sec}$. groups to be significant $(p<.05)$; the difference between the $1 / 2$ sec. and Random groups to approach significance $(p<.10)$; and the difference between the $1 / 2$ sec. group and what would be expected by chance alone to approach significance $(p<.10)$. All other differences did not approach significance.

The CS-US interval data for the Shock-Different groups differed extensively in both acquisition and extinction. Although the difference in acquisition only approached significance $(F=2.97 ; d f=3 / 20 ; p<.10)$, the difference in extinction was significant $(\mathrm{F}=3.09$; $\mathrm{df}=$ $3 / 20 ; p=.05)$. When the shock was $7 \%$ more in the CS compartment, the $1 / 2 \mathrm{sec}$. and $5 \mathrm{sec}$.groups in acquisition tended to spend more trials in the compartment with less shock, and the 0 sec. and Random groups to spend about $50 \%$ of the trials in each compartment. A Duncan Range test on the acquisition data showed the differences between the $1 / 2 \mathrm{sec}$. and $0 \mathrm{sec}$. groups, between the $1 / 2 \mathrm{sec}$. and Random groups, and between the $1 / 2$ sec. and chance to be significant $(p<.05)$. The difference between the $1 / 2 \mathrm{sec}$. and $5 \mathrm{sec}$. groups approached significance $(p<.10)$. In extinction, the $1 / 2$ sec. group but, interestingly, not the $5 \mathrm{sec}$. group continued to spend far more trials in the compartment with less shock. Moreover the Random group, for whom only acquisition and extinction were the same, did spend somewhat more trials in the less-shock compartment. The Duncan Range test on the extinction data revealed the differences between the $1 / 2 \mathrm{sec}$. and 0 groups, between the $1 / 2 \mathrm{sec}$. and $5 \mathrm{sec}$. groups, and between the $1 / 2$ sec. group and chance to be significant $(p<.05)$. All other differences did not approach significance.

\section{Discussion}

The results indicate that: (a) Ss tend to prefer a $1 / 2$ sec. or a 5 sec. warning signal over no signal in an unavoidable shock situation; (b) Ss with a 0 sec. signalshock interval behave similarly to those with a random interval by not preferring a signal situation over a nosignal situation; and (c) Ss do not tolerate more shock ( $7 \%$ more) in order to obtain a warning signal than they have to tolerate in a no-signal situation.

Considering first the preference for a warning signal-although the unusually large individual variability, as compared with the Lockard (1963) study, tended to obscure the findings - the $5 \mathrm{sec}$. and particularly the $1 / 2 \mathrm{sec}$. group did spend more trials in the CS compartment when the shock was the same in both compartments. In the Lockard (1963) study, the shock was completely eliminated in extinction and the preference dropped to the chance level. In the present study, the shock was maintained in extinction on a random schedule and tended to perpetuate the trends developed in acquisition.

However, when more shock was presented in the CS compartment than in the other compartment, the $5 \mathrm{sec}$. and particularly the $1 / 2 \mathrm{sec}$. group tended to avoid the CS compartment. The data indicate that preference for a warning signal is not a strong phenomenon in that the Ss did not tolerate the $7 \%$ more shock to obtain the warning signal. The avoidance of the CS compartment continued into extinction for the $1 / 2$ sec. group but not for the 5 sec. group. One might conjecture that the $7 \%$ difference in shock (.236 ma compared to $.221 \mathrm{ma}$ ) was a barely perceptible difference; and that in acquisition, the CS onset $1 / 2$ sec. before more-shock was more of a discriminable stimulus than the CS onset $5 \mathrm{sec}$. before more-shock. Such a conjecture would be consistent with the findings that in acquisition the $1 / 2$ sec. group did avoid the CS compartment more than the $5 \mathrm{sec}$. group; that in acquisition the $0 \mathrm{sec}$. and Random groups spent about an equal number of trials in each compartment; and that the Random group, for whom only acquisition and extinction had been identical, in extinction did begin to avoid the CS compartment with more shock.

\section{References}

Campbell, B. A., \& Teghtsoonian, R. Electrical and behavioral effects of different types of shock stimuli on the rat. J. comp. physiol. Psychol., 1958, 51, 185-192.

Duncan, D. B. Multiple range and multiple $\mathrm{F}$ tests. Biometrics, $1955,11,1-42$.

Knapp, R. K., Kause, R. H., \& Perkins, C. C., Jr. Immediate vs delayed shock in T-maze performance. J. exp. Psychol., 1959, $58,357-362$.

Lockard, Joan S. Choice of a warning signal or no warning signal in an unavoidable shock situation. J. comp. physiol Psychol., 1963, 56, 526-530.

Perkins, C. C., Jr., Levis, D. J., \& Seymann, R. Preference for signal-shock vs shock-signal. Psychol. Rep., 1963, 13, 735-738.

\section{Notes}

1. This study was conducted at the University of Wisconsin in partial fulfillment of the Ph.D. degree in psychology. To that end, the author wishes to thank Dr. Leonard E. Ross for his invaluable help.

2. Department of Neurosurgery. 